\title{
Silk Road 4.0: Initiative Transformation for Chinese Silk Enterprise
}

\author{
Mao Ning ${ }^{1}$ Michael McAleer ${ }^{2}$ \\ ${ }^{1}$ China-Asean International College, Dhurakij Pundit University, Thailand \\ ${ }^{2}$ Department of Quantitative Finance, National TsingHua University, Taiwan \\ Erasmus School of Economics, Erasmus University Rotterdam, Netherlands \\ Department of Quantitative Economics, Complutense University of Madrid, Spain \\ Institute of Advanced Sciences, Yokohama National University, Japan \\ ${ }^{*}$ For financial support, the second author acknowledges the Australian Research Council \\ and the National Science Council, Ministry of Science and Technology (MOST), Taiwan.
}

\begin{abstract}
This paper searches the breakthrough point to improve the current dilemma of Chinese silk enterprises. Creswell (2012) stated that the case study methodology is a qualitative approach that explores one or multiple cases through in-depth data collection from multiple sources. This paper use case studies for inductive reasoning that is feasible for marketing strategies, and provides an upgrading strategy to help Chinese silk enterprises to transform their market positioning and operating modes to obtain better development opportunities.
\end{abstract}

Keywords: Export-Oriented, China, Silk, Marketing Strategy, II4 (Initiative- Industry 4.0).

\section{Introduction}

In history, Silk Road crossed the mountains and deserts to connect China and Europe. In the 19th Century, the German geologist Ferdinand Von Richthofen first gave the name Silk Road to this route (Xiaoming, 2006). Silk products were always the most important goods in Chinese foreign trade, even compared with tea and chinaware.Based on a rigorous technical blockade, China had a monopoly in the silk business worldwide for nearly one thousand years (Elizabeth, 2002).

Recently, the dominance of the Chinese silk industry has been challenged, for several reasons: (i) many developing countries had lower labor and production cost; and (ii) the Chinese silk industry still has problems that need to be resolved, such as a shortage of high value-added products, over-dependence on overseas markets, as well as a lack of retail channels.

Silk is of historical significance and symbolic importance to China. For example, the Chinese government has selected the Silk Road to represent its own development strategy, such as "One Belt and One Road". Special meaning is attached to the Silk Road Economic Belt and $21^{\text {st }}$ Century Maritime Silk Road.

\section{Backgrounds}

\subsection{Advantages of the Chinese Silk Industry}

The silk industry has been a phenomenon, in that many countries demand Chinese silk even though there is not an established industrial chain. Developed countries have no silk manufacturing, while developing countries generally do not have qualified manufacturing opportunities. Preeya (2013) identified silk production as being categorized into three main stages, namely: (i) the upstream industry covers sericulture farming, silk rearing and silk reeling; 
(ii) the weaving, dying and printing has constituted the midstream industry; and (iii) the downstream industry includes design, production, retailing and marketing. Chinese silk production and export amounts are close to $54 \%$ of world output. Moreover, Chinese sericulture has over 20 million workers. In short, China is the only country worldwide that has an integrated silk industry.

\subsection{Dilemma of Chinese Silk Industries}

In China, over $80 \%$ of silk products are exported to overseas market. When an economic downturn or financial crisis occurs, the Chinese silk industry faces devastating blows. The Chinese silk industry relies on low labor and raw material costs,so that when the government promulgates new Labor Law to increase wages, most silk enterprises will lose their competitive edge. Today, over three thousands silk enterprises exist in China, but over $90 \%$ are township or village enterprises that use price wars to destabilize market shares and seriously disrupt normal market prices.

In general, new market creation and product innovation are the most important approaches to solve the dilemma. As in internet marketing and innovation design, for a long time the Chinese silk industry has been struggling in this dimension.

\subsection{Chinese Silk Industry}

Jiaxin Silk Crop Ltd (abbreviated name is JSCL) is the only listed company in the China silk industry, and is a typical case of research. JSCL is a labor-intensive enterprise, with over $80 \%$ of its products having been exported to overseas markets annually. In recent years, its revenues have continued to fall. For example, its operating costs increased substantially from $5.48 \%$ in 2013 to $10.22 \%$ in 2015 .

The causes of JSCL's problems are as follows: (i) dependence on the export-oriented economy; (ii) operating by B2B transactions, without characteristics of goods; and lacking loyal consumer and brand awareness. Therefore, research questions have been proposed, such as: (a) How to reduce the dependence on exports? (b) How to propose a rational and improved business model? (c) How to create the characteristics of the silk goods and to establish an appropriate brand image?

\section{Traditional Transformation Approach}

First, the domestic market can increase the enterprise's revenue and reduce the losses through exchange rate fluctuations. Increasing brand visibility in the domestic markets will also improve the confidence of investors, and assist the silk enterprises to obtain additional capital resources. The domestic market is different from export market, as the former needs ready-to-use products to replace the products of foreign brand dealers. Moreover, international marketing does not need companies to establish and maintain distribution channels, but domestic marketing needs such channels.

Second, a brand is essentially a promise, as products are made in factories but brands are created in the mind. Brands represent the attributes, quality, price, reputation, image, and self-expression of the underlying products. The brand attribute must be focused on a narrow and specific product 
range, such as underwear experts or jeans masters in order to convince and inform customers about the qualities of the companies.

Third, consumers are increasing demand for brand sensibility, especially in China. Compared with developing countries, China has more Parvenus and Poseurs consumers (Luxury 4P taxonomy, Han, Nunes \& Dreze, 2010). As distinct from the Patricians group, Parvenus and Poseurs consumers intend through consuming products to express their economic power, and to obtain greater social status, although much of the time this status is purely psychological.

JSCL must consider Veblen effects (The Theory of the Leisure Class, Veblen, 1899), the Snob effect, and the Bandwagon effect. The Veblen effects mean that consumers purchase higherpriced goods even when similar lower-priced substitutes are available. The Snob effect means that the demand for a product by a high income segment varies inversely with demand by the lower income segment. The Bandwagon effect means that individuals will act primarily because other individuals are doing the same thing, regardless of their beliefs. According to the Hofstede cultural dimensions theory (Hofstede, 1973), China is a collectivist country, so that interpersonal effects are expected.

Fourth, compared with international marketing, the domestic market is more concerned with the relationship between enterprises and consumers. For example, boutiques, franchise stores, department stores, and warehouse stores are four mainly retail channels. However, every distribution channel has established a different relationship between sellers and buyers. If JSCL chooses departmental stores as channels, the company image will be established according to the associated store image. Franchise stores and warehouse stores always operate according to middle brands and fast fashion so that, if JSCL wants to enter the high-end retail market, it must ignore these kinds of channels.

Meanwhile, push and Pull factors have emerged as an important method for interpreting retailers' motives for expanding into domestic and foreign retail markets. Retailers are pulled towards a foreign market and/or are "pushed" out of their home market in order to further their growth objectives (Hines, 2007). Like JSCL, it presently lacks the reputation and loyalty of consumers in the domestic market, so it should cooperate with upscale department stores or traditional department stores as a shortcut to establish its enterprise image. Opening some boutique stores overseas can also improve the image from the perspective of domestic consumer psychology.

\section{II4 Strategies (Initiative- Industry 4.0)}

The traditional transformation approach needs mass economic inputs, so that it is not suitable for every company, especially for struggling companies such as JSCL. Internet B2C commerce reduces the cost of transactions as it allows customers to access information more easily about different products and sellers (Different Businesses, 2011). Compared with mass upfront investment to enter the bricks and mortar retail markets, the e-commerce platform has helped many less financially poor companies to run businesses. Taobao.com is a famous example, as it helps over one million Chinese families to enter the middle class, and also promote the Chinese package industry, the logistics industry, and even the fast food industry. However, the B2C orC2C platform cannot solve all the underlying problems, especially such as product differences from consumer needs, namely haute couture or fast fashion. 
Compared with the IT industry, some traditional industries in China are stagnant. The Chinese government has guided traditional industries to develop intelligent production. Examples include "Created in China" to replace "Made in China", but the asymmetric information is a problem to impede these good intentions. In the past, manufacturer had to know that meeting every customer's needs is impossible. Therefore, as in the case of JSCL, concentrating on only a limited number of products cannot possibly meet all the requirements of consumers.

Employing Industry 4.0 will change this situation as Industry 4.0 provides the automation and data exchange in manufacturing technologies. It includes cyber-physical systemsand cloud computing. Based on this technology, customers and enterprises will connect with each other at very low cost, so that demand of natural personalities would be greatly enhanced. Nowadays, consumers increasingly prefer personalized products, but personalized products frequently have extremely small requirements that need the Industry 4.0 platform to capture accurately customer needs and rapid production.

China has a complete silk industrial chain and huge industry scale, so that rapid production is an obvious advantage of Chinese enterprises. The only problem is how to completely open up and link systems like ERP (Enterprise Resource Planning) and MES (Manufacturing Execution System), and allow enterprises from the complete automation and portion information period move toward complete automation and complete information.

JSCL needs to establish an online service platform, then let the platform connect with production equipment, use the RFID (Radio Frequency Identification) to cover the product information, and then use the information for intelligent production. JSCL's role should be like an intelligent enterprise, receiving the information from domestic or overseas consumers, and then producing the customers' orders.

When the online information system and automated production system are combined, JSCL can re-position itself as a cloud enterprise. JSCL would only focus on silk product innovation and service upgrade, so it would not need to develop its own server and online platforms. A direct hiring of the cloud service would save time and money. Meanwhile, JSCL as a cloud silk factory could also accept orders from other online platforms.

\section{Conclusions}

Online platforms have helped many poor Chinese economically, so there is reason to expect it to help Chinese enterprises in a similar manner. Industry chains and industry scale are both advantageous for Chinese silk manufacturing. How to find the right way of exerting these advantages should be more important than how to recognize them. The Industry 4.0 mode provides a feasible way of developing struggling Chinese enterprises, including the silk industry.

\section{References}

[1] Elizabeth.G: Along the Silk Road, University of Washington Press Publishing, Seattle (2002).

[2] X. Xiaoming, L.Zhenguo and L. Heping: Gansu Grottoes on the Ancient Silk Road, Beijing Foreign Languages Press Publishing, Beijing (2006). 
[3]P.Preeya, W.Winai, and M. J.Lalit: submitted to Journal of Fashion Marketing and Management (2014).

[4] Han. Y.J, Nunes. J.C, Dreze. X, Signaling: submitted to Journal of Marketing (2010).

[5] Veblen. T. B: The theory of the leisure class, Houghton Mifflin, Boston (1899).

[6] Hofstede. G, Cultures and organizations: software of the mind, 1991, London McGrawHill.

[7] Hines.T and Bruce.M: Fashion Marketing, Elsevier Publishing, Oxford (2007). 